$\stackrel{W}{N}$

Global Journals Inc

(3)

GLOBAL JOURNAL OF MANAGEMENT AND BUSINESS RESEARCH: A

ADMINISTRATION AND MANAGEMENT

Volume 20 Issue 8 Version 1.0 Year 2020

Type: Double Blind Peer Reviewed International Research Journal

\title{
A Review of the Challenges of Energy Sector and Prospects of Renewable Energy Utilization in Yemen
}

By Ensejam Ibrahim Hashim Alkipsy, Valliappan Raju \& Harish Kumar

Limkokwing University of Creative Technology

Abstract- The study attempts to review the potentials and the challenges confronting the utilization of renewable energy resources in Yemen. The paper on specifics tries to find out how Yemen can increase the country's electricity generating capacity, as well as to explore the possibility of utilising renewable energy in the Republic of Yemen. Content Analysis has been used in planning the subject of this research and analyzing the whole data collected from the relevant secondary sources. The design in this particular research is used to demonstrate understanding and to study current energy challenges and how alternative renewable energy such as solar energy can reduce the need for Yemen to build new fossil fuel generation power. The study reveals that Yemen has unexplored potential in terms of wind energy which can be developed to produce nearly 14, $214 \mathrm{MW}$, solar energy with the potentials of producing about 2210MW, while geothermal energy can produce about $28.5 \mathrm{GW}$ of electricity.

Keywords: energy sector, renewable energy resource, wind energy, solar energy, yemen.

GJMBR-A Classification: JEL Code: M10

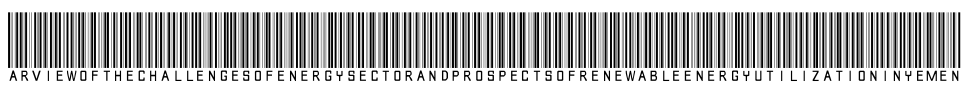

Strictly as per the compliance and regulations of:

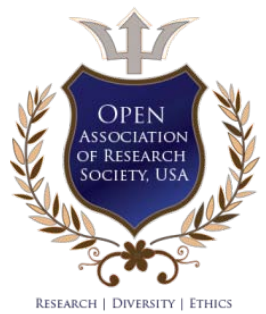

(c) 2020. Ensejam Ibrahim Hashim Alkipsy, Valliappan Raju \& Harish Kumar. This is a research/review paper, distributed under the terms of the Creative Commons Attribution-Noncommercial 3.0 Unported License http://creativecommons.org/licenses/by$\mathrm{nc} / 3.0 /$ ), permitting all non-commercial use, distribution, and reproduction in any medium, provided the original work is properly cited. 


\title{
A Review of the Challenges of Energy Sector and Prospects of Renewable Energy Utilization in Yemen
}

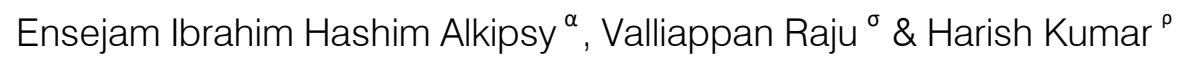

\begin{abstract}
The study attempts to review the potentials and the challenges confronting the utilization of renewable energy resources in Yemen. The paper on specifics tries to find out how Yemen can increase the country's electricity generating capacity, as well as to explore the possibility of utilising renewable energy in the Republic of Yemen. Content Analysis has been used in planning the subject of this research and analyzing the whole data collected from the relevant secondary sources. The design in this particular research is used to demonstrate understanding and to study current energy challenges and how alternative renewable energy such as solar energy can reduce the need for Yemen to build new fossil fuel generation power. The study reveals that Yemen has unexplored potential in terms of wind energy which can be developed to produce nearly 14, $214 \mathrm{MW}$, solar energy with the potentials of producing about $2210 \mathrm{MW}$, while geothermal energy can produce about $28.5 \mathrm{GW}$ of electricity. These could be tapped to fill the country's energy gap. Unfortunately, the country's solar energy market is still lagging behind in producing maximum capacity that will help the country to improve its short-term energy supply in rural areas based on a number of preventive factors including a lack of policy and facilitator framework from the government to fully support solar energy initiatives to help the country improve its energy per capita.
\end{abstract}

Keywords: energy sector, renewable energy resource, wind energy, solar energy, yemen.

\section{InTRODUCTION}

$\mathrm{t}$ $\mathrm{t}$ becomes too outdated for many countries to continue to depend on fossil fuels as the only means of producing electricity. For this reason therefore, most developed countries including Yemen continue to find alternative ways in which their power generation capacity can be increased or enhanced. According to available record obtained revealing the 2016 statistics on energy generation capacity and overall energy utilization issued by the International Energy Agency (IEA) and the Institute of Energy (EI) confirmed that a number of countries are steadily reducing their over reliance on fossil fuels in generating electricity as a result of the negative impact this have on the environment, even though fossil fuel had greater

Author $\alpha$ : Research Scholar, Limkokwing University of Creative Technology, Malaysia. e-mail: ensejam.h.kipsi@outlook.com

Author б: Senior Lecturer, Limkokwing University of Creative Technology, Malaysia.

Author p: Planning Supervisor Dove Energy Ltd, Sanaa, Yemen. dominance in the years backin fulfilling the energy demands of the 21 st century. The tremendous decrease in reliance on fossil fuels as a means of generating electricity led to the prominence solar energy internationally and acceptance in a global renewable energy mix (Hammarström, 2012).

Renewable energy is the new keyword for many country alternative ways to generate cleaner energy. The $21^{\text {st }}$ century is witnessing a transition in energy source because of environmental concern, limitations on the supply of the fossil fuel, prices and changes in technology (Timmons, Harris, \& Roach, 2014).In view of this fact many developing countries including Yemen are planning to adopt renewable energy alternatives such as solar energy and wind energy among other renewable energy alternatives to tackle the shortage of electricity and its distribution by minimizing their greenhouse gas emissions. The renewable energy in form of solar energy or wind power is proven to be cost -efficient and profitable for a long period of time (Cook et al., 2010).

As a result of cutting cost and technology learning, it has been estimated that photovoltaic accounts between 30 and $50 \%$ of all the global generation mix by 2050 with an estimated potentials of generation through PV by 2035. As compared with BNEF 2040 estimates where about 34\% world electricity generation will be through the combination of wind and solar generation, while the EIA estimated generation $31 \%$ by all renew ables (Creutzig et al., 2017).It is imperative to Yemen to target the global energy production best practice, Yemen do not have to build more fossil power generation plant as renewable energy is now more environmentally friendly and more efficient way, to obtain cleaner energy generation; this will more importantly help Yemen to provide enough electricity to its unproductive rural areas.

\section{a) The challenges of the energy sector in Yemen}

In this era of global warming, together with increasing energy demand and lack of fuel stocks (especially fossil fuels), non-renewable sources are used at extraordinary and inefficient rates. These resources will be exhausted in the foreseeable future. Such situations force countries of the world to search for renewable energy sources. In recent times Renewable energy technology considering its technology, economic 
benefits and environmental concern has been more sustainable. For these reason the main concern is centered on harnessing the alternative energy resources to overcome the inelastic energy demand globally.

Considering the country's human development indices, Yemen for more forty six years beginning from 1971 up to 2016 was categorized under the least developed countries (LDC), basically due to its very weak human capital assets, low gross national income (GNI) and current political instability exacerbated by the country's economic vulnerability (UN, 2016). Yemen's per capita GDP (Gross Domestic Product) according to World Bank Group (2013) is not more than US\$1,086 per year. Characterized by high malnutrition, illiteracy and child mortality rate, with pervasive unemployment rate Yemen in recent times is experiencing an increase which put at $2.47 \%$ and by 2015 the country's population is estimated at 26 million according to the country's online published data (CIA, 2016). Yemen's the economic stability has been at stake due largely to escalating economic vulnerability (El Mallakh, 2014). The most outstanding challenges facing the growth and development of the economy of Yemen comprises of its monolithic economy which is mainly the oil reserves, and its dwindling market. Additionally, nearly $75 \%$ of the people in Yemen are poverty striking rural dwellers. The poverty situation in the country is characterized by the absence of basic social amenities such as health, energy and education (Ali et al., 2014). Accordingly, Yemen's population has the lowest access to electricity supply with uneven electricity distribution between urban and rural settlers. Although the rural population accounted for nearly $75 \%$ of the total population, yet have less $23 \%$ have access to electricity as compared to $25 \%$ of urban population which enjoying about $85 \%$ of the electricity supply (UNDP 2014, World Bank Group, 2013).

Yemen in recent times encountered serious shortage of power supply which does not meet up with its infrastructural as well as population needs. As at 2009, Yemen had only 1.6 GW electricity installed capacity with an estimated power supply deficit of 0.25 GW to meet with the demand (Qasem 2018; Sufian, Ogutcu, \& Barra, 2017). The projected electricity demand by the year 2020 was put at $3.538 \mathrm{GW}$ as contained the Yemen's power development plan (PDP) aimed at replacing the retiring units as well as meet the demand sufficiently(Ali, Alkadasi, \& Khoday, 2014). However, as at 2011 the country electricity capacity demand rather fell to below 70 percent of the total capacity which was caused by riots against Yemen government, oil industries strike, as well as withdrawals of foreign expatriates (Qasem 2018; Rawea \& Urooj, 2017).The electricity supply gap against demand is estimated about 500 MW in 2013(Ali et al., 2014; Sufian et al.,
2017). By 2015 the power supply worsen as a result of domestic and external conflicts (Qasem 2018).

The sustainable performance of Small and Medium Enterprises as well as small scale industries has seriously been hampered due to constraints from the energy sector in Yemen. As such, many of the SME were closedown in 2011 due largely to the inaccessibility of electricity and political crisis resulting in the massive retrenchment of workers. Whereas in the rural areas the livelihood potentials of the poor people. The absence of electricity has reduce the income generation alternatives of the poor, as well as the quality of the education and health services (Ali et al., 2014). There is the need to look ahead beyond the war and conflict in Yemen to overcome the impediments associated with electricity generation as to identify the best options of resolving the problems (Qasem 2018).

The enormity of the problem as well as insufficient electricity supply in Yemen is rooted in its over reliance on fossil fuel such as Mazot (heavy diesel crude oil) and liquefied natural gas in spite of their economic and environmental consequences (Jahangiri, Ghaderi, Haghani, \& Nematollahi, 2016). Geographically, the greater part of Yemen being rural constituting about $75 \%$ benefitted only $23 \%$ of the total electricity supply (Sufian et al., 2017). This contributed to the enormity of power distribution challenges, added to its low and feeble industrial activity arising from epileptic power supply, and predominance of electricity power supply mainly for domestic use. Figure 1 shows the profile of Yemen's electricity supply.

\begin{tabular}{|c|c|c|c|c|}
\hline $\begin{array}{c}\text { Industry \& } \\
\text { Agriculture }\end{array}$ & Commercial & Urban Household & $\begin{array}{c}\text { Rural House } \\
\text { Hold }\end{array}$ & Others \\
\hline $11 \%$ & $17 \%$ & $55 \%$ & $3 \%$ & $14 \%$ \\
\hline
\end{tabular}

\section{Yemen Profile of Electricity Consumption}

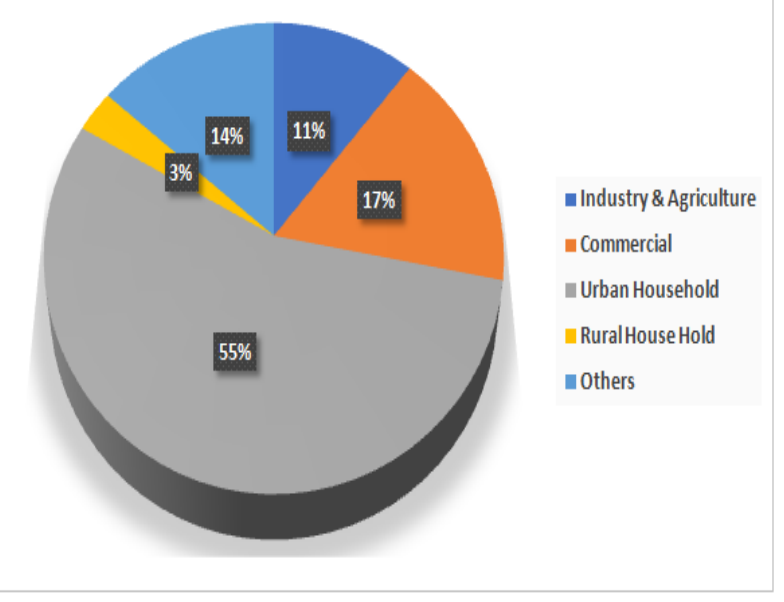

Source: Adopted from Qasem (2018)

Figure 1: Yemen's Profile of Electricity Consumption 
These challenges contributed to the enormity of the electric power supply deficit in Yemen. Although the country has bountiful renewable energy resources including solar, wind, geothermal, hydropower and biomass energy which can be harnessed to generate the electricity that will remedy the energy deficit (Al Kubati, Mattash, Alnethary, Minissale, \& Vasseli). Renewable energy technologies provides a lot of long term benefits comprising of energy security, job creation, business opportunities, sustainable development and prevention of global warming(Al Kholidi 2013).This paper therefore, attempts to review the current status and the challenges confronting the utilization of renewable energy resources in Yemen. The paper on specifics tries to find out how Yemen can increase the country's electricity generating capacity, as well as to explore the possibility of utilising renewable energy in the Republic of Yemen.

\section{il. Methodology}

As this study attempt to review the current status and the challenges confronting the utilization of renewable energy resources in Yemen, and specifically to find out how Yemen can increase the country's electricity generating capacity, as well as to explore the possibility of utilising renewable energy in the Republic of Yemen. The researcher entirely relies on published secondary data from reputable sources including the Energy Institute, the World Bank, the CIA, and the UNDP including review of published articles from reputable international journals such as ISESCO Science and Technology journals, Future cities and Environment journal, Emerald and JSTOR, Springer, Elsevier amongst others.

Content Analysis has been used in planning the subject of this research and analyzing the whole data collected from the relevant secondary sources. The design in this particular research is used to demonstrate understanding and to study current energy challenges and how alternative renewable energy such as solar energy can reduce the need for Yemen to build new fossil fuel generation power. Themes derived from secondary data sources including articles and journals were systematically arranged to present clear research design. The 'Design' formulated to minimize the tendency in research and design enhanced the authenticity of the research in which the research inquiry is investigated. This study has chosen content analysis method by selecting the relevant content of the various literatures related to this study; and the literature review enable the overall development of the study which ordinarily centered on theoretical backgrounds and foundations. Data collected from previous studies were analyzed this helped in answering to research inquiries to obtain results.

\section{Current Energy Resources in YEMEN}

Yemen has abundant energy resources which comprises of the following in Yemen consist of the following(Al Ashwal 2016); Oil is the main source of energy. Oil was discovered in 1984. The total production of Yemen now has reached an average of 439,000 bpd. $50 \%$ of which is produced in Al-Masila and the other $50 \%$ is produced in the rest fields. Yemen has been exporting oil since the nineteen eighties. The current certified gas reserved in Yemen is18.215 tcf. From this amount 9.5 tcf is allocated for export. In actuality, Yemen has significant deposits of gas but these reserves have not been developed or effectively utilized due to the absence of appropriate infrastructure and the inability of the government to decide on the most economic options for the gas. Now42152 t per month of LPG are currently produced. This amount of production was reached due to participation of private sector in building bottling plants in different locations of the country and distribution of gas bottles. Actually LPG bottles are available now everywhere in the country. More than $80 \%$ of national market is covered(Al Ashwal 2016).

a) Renewable energy Potentials in Yemen

Yemen has huge renewable energy potentials. According to a study conducted by Consultants Lahmeyer International, Germany these potentials comprises of the following (Al Ashwal 2005, 2016):

\section{i. Wind Energy}

Yemen has a long coastal strip of over than $2500 \mathrm{~km}$ long and an average width of $45 \mathrm{~km}$ along the Red Sea, and the Arabian Sea. These coastal areas have an annual wind speed average of more than $8 \mathrm{~m} / \mathrm{s}$. There is a good potential for making wind farms on the coastal strip as well as on the offshore areas. One of the most suitable coastal areas is Al-Mokha Zone, Taiz, Yemen which has favorable conditions of wind. Unfortunately the available meteorological data does not contain enough information about the wind in various locations in the country. Geographic Nature of Yemen has helped to generate daily wind with reasonable duration and speed. The well-known phenomena of local wind patterns are clearly realized in Yemen. These are: Sea Breezes and the Mountain-valley wind (Qasem 2018)

The most populated areas of Yemen are Mountain-Valley areas. There are a great number of small villages shuttered on the top of mountains where altitude is $1200 \mathrm{~m}$ above sea level or less, the electricity supply could be generated most economically by installing wind-turbine generators. The wind is available almost whole year which permits to use wind turbines in decentralized fashion to produce electrical energy for house hold use in rural areas. In some areas the 
availability of sun and wind is in contrast. This situation can encourage proposing Wind-PV hybrid systems. The coastal areas high speed wind continues for more than six months that September to March. This condition is a good indicator to propose wind farms combined with Diesel generation, with PV system or connected to the grid. Further study for wind availability and daily wind speed is required to precisely assist wind generation economics. Initial estimations showed that around 14,214 MW could be developed at assessed wind farm sites. Economically attractive sites were those with more than 3500 full load hours per year. A capacity of around 2507 MW could be developed at these sites which could generate around 8293 GWh of electricity per year(Al Ashwal 2005).

In order to produce clean energy, Yemen, in line with other Middle East countries and other developing nations, the country is looking for other alternatives such as solar and wind energy, to reduce the country's rise in solvent carbon as it raises great concern for many parties related stakeholders (Ali et al., 2014).

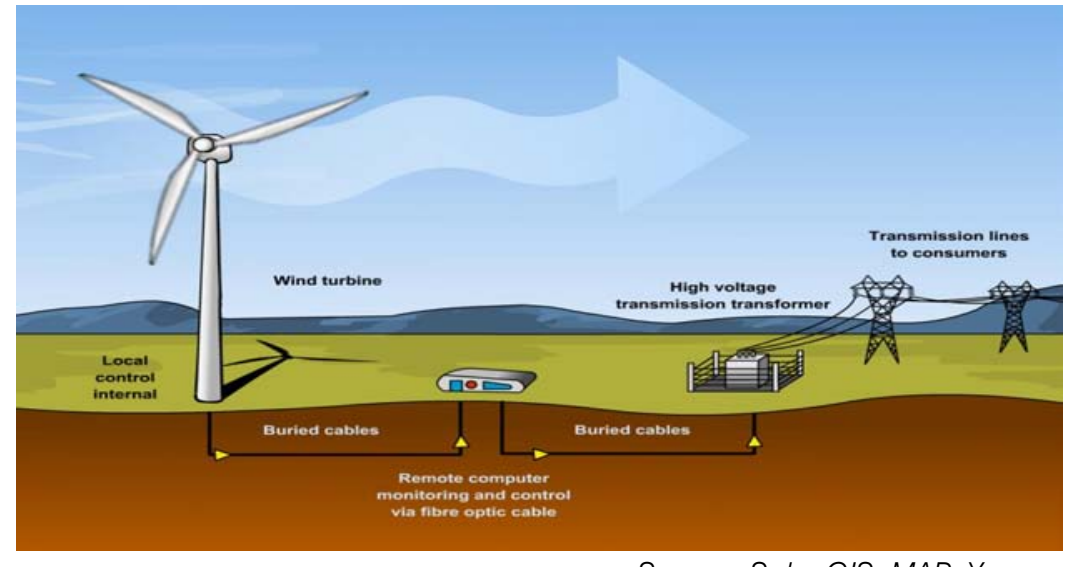

Source: Solar GIS_MAP Yemen

Figure 2: Wind Powered Electricity Generator

\section{ii. Solar Energy}

For a country under obstruction and suffering from a severe power crisis, solar energy is considered as a perfect alternative energy source to solve an important part of this crisis; furthermore, the source is eco-friendly. In the last years from 2014 - 2016 AD solar energy systems have seen unprecedented developments in addition to lower price rate dramatically (Rawea \& Urooj, 2017).

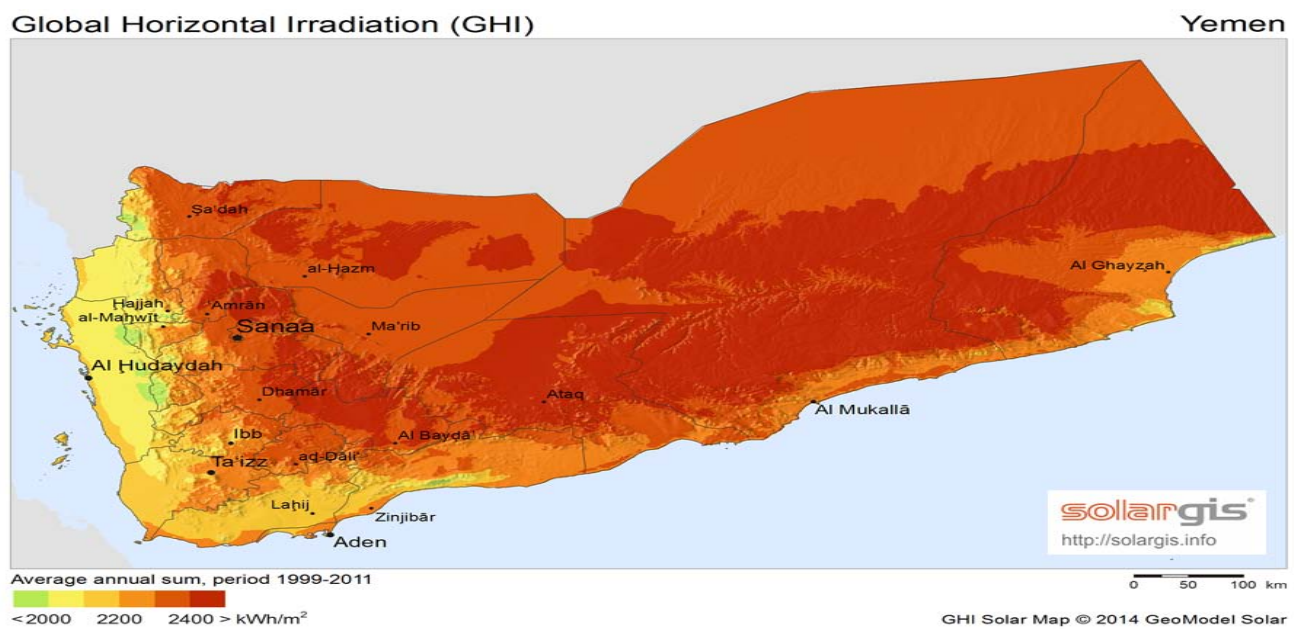

Source: Jahangiri et al. (2016)

Figure 3: Average solar radiation in the middle- east

\section{iii. Geothermal Energy}

Yemen is situated near three tectonic boundaries which are among the most active in the world, viz. the Gulf of Aden, the Red Sea and the Eastern African Rift System. These three tectonic plates meet in a triple junction creating high geothermal gradient, and subsequently geothermal energy potential was estimated to be $28.5 \mathrm{GW}$ (Al Ashwal 2016). The country has more than seven areas of natural hot springs of water. In addition Yemen is specified as one of the countries having high heat flow. The heat flow reflects the potential of geothermal energy(Al Ashwal 2005). 
The world map of heat flow shows that Yemen and Italy have equal potential of heat flow $\left(60 \mathrm{~mW} / \mathrm{cm}^{2}\right)$. The total capacity of geothermal power installed in Italy is more than500 MW which clearly demonstrates the high potential of geothermal energy in Yemen. In 1984 a study financed by World Bank was performed by Geothermex Inc. The study was directed to investigate the availability of geothermal energy in Dhamar area (100 km south of Sana'a). The study concluded that it is possible to build a geothermal power station with a capacity of 125-250 MW. Such power for Yemenis considerably high in relation to the total installed power (Al Ashwal 2005).

\section{iv. Biomass Energy}

For several centuries Yemen is well- known as an agrarian state as the main component of the country's economy, Yemen is famous for being an agricultural country. The over concentration of activity in this sector will result in the monumental waste of resource. Moreover, the waste related with the industrial production has the capacity to affect the environment if not handle with care. The generality of these waste types could be put into use potentially to generate biomass energy to be used for many purposes such as gasification for the electricity generation or for the cooking purposes. This technology can be used to make biogas plants in major cities such as Sana'a, Aden, and Taiz, to produce electricity from biogas instead of diesel or heavy fuel (Mazot) used mainly in the diesel power plants in Yemen. For example, if we take the garbage waste that is picked up by the garbage trucks on a daily basis in Sana'a city which occupies more than two millions residents, this will be approximated by 1,000 tons of trash. This trash can be delivered to specialized digesters to produce biogas which is composed of $60 \%$ methane $(\mathrm{CH} 4)$ and $40 \%$ carbon dioxide (CO2). For every ton of waste we estimate to get an amount of $50 \mathrm{~m}^{3}$ of biogas. So, 1,000 tons of trash will be capable of producing nearly to generate $5,000 \mathrm{~m}^{3}$ of biogas per day around Sana'a district (Qasem 2018), this is equals to $30,000 \mathrm{KWh}$. This production capacity is estimate to have provided nearly 5,000 households with 6KWh average electricity need.

\section{b) The Prospect of Renewable Energy in Yemen}

There is an unparalleled and massive potential of many renewable energy sources for the Yemen Republic. Many researches include research from the Ministry of Energy, Evaluation and Evaluation with the Economic and Yemen National Union, and (CDM), - The Clean Development Mechanism has shown that Yemen has enormous potential for renewable energy. This report shows that there is a huge potential for renewable energy, especially for solar, wind, biomass and geothermal. The above-mentioned renewable energy sources are noted by Brehony and Al-Sarhan (2015) to be very much in the country and should be utilized and used to meet the challenges of electricity shortages in Yemen and towards reconstruction of the country from political, economy and society. Once Yemen can rapidly adjust the migration from the country's dependence on fossil fuels into renewable and cleaner energy, it will help the country's economy in general to meet its objective of achieving the target of lower emissions of economic growth.

Yemen's Ministry of Energy \& Energy responsible for electricity distribution recently produced research published on the physical prospects and hypotheses of renewable energy options for Yemen. Based on his research, the potential of renewable energy for Yemen as highlighted by the Ministry of Electricity includes the following: Wind, Geothermal, and Solar electricity, Biomass-landfills, Hydroelectric and thermal Suria (MOEE - Ministry of Energy \& Energy, 2014 -2016 data). Table 1 below provides an illustration of the renewable energy sources above and features different from their potential in terms of hypothesis and physical.

Table1: Republic of Yemen's Renewable Energy Potentials

\begin{tabular}{|c|c|c|c|}
\hline $\begin{array}{c}\text { Renewables Resources Hypothetical } \\
\text { Potentials }\end{array}$ & (MW) & $\begin{array}{c}\text { Gross Technical } \\
\text { Potentials } \\
\text { (MW) }\end{array}$ & $\begin{array}{c}\text { Practical Technical } \\
\text { Potentials } \\
\text { (MW) }\end{array}$ \\
\hline [Solar electricity] & $(2,446,000)$ & $(1,426,000)$ & $(18,600)$ \\
\hline [Wind energy] & $(308,722)$ & $(123,429)$ & $(34,286)$ \\
\hline [Hydropower -'Major Wadies'] & $(12-31)$ & $(11-30)$ & - \\
\hline [Biomass-landfills] & $(10)$ & $(8)$ & $(6)$ \\
\hline [Solar thermal-Solar Water Heater] & $(3,014)$ & $(278)$ & $(278)$ \\
\hline [Geothermal] & $(304,000)$ & $(29,000)$ & $(200)$ \\
\hline
\end{tabular}

Source: (UNDP Publication on Yemen: Prospects of Solar Energy in Yemen/Yemeni Joint Socio-Economic Evaluation)

It is imperative to note that among all the renewable energy sources highlighted in the Yemen Republic, only solar energy has the largest gross technical prospect. However, Wind power is much higher than solar energy in terms of its potential in abrasive abilities. Waltz works (2015) and Ali et al., (2014) show that the average radiation for solar energy is around 18-26 MJ / $\mathrm{m}^{2}$ per day over 3,000 hours per year clear blue sky and hypothetical potential for 
electricity comes from solar use CSP) - concentrated solar energy presents about 2.5 million Mega Watts.

Accordingly, it is noteworthy that the current potential of 308,000 Mega Watts can be achieved by Wind Power. While geothermal potential is estimated at around 304,000 Mega Watts. However, the entire secondary data collected on Yemeni electricity generating both reputable sources suggests that the current mix of energy in the Yemen Republic is largely controlled by $99.91 \%$ by fossil fuels while the current portion for renewable energy in the national energy market is expected to be around 0.009 \% (UNDP, 2014;
Ali et al., 2014). However, a new target will be achieved by the Yemen government in 2014 - 2025 on the diversification of national energy generation capacity until the 15\% increase has been set by the 'National Strategy for Renewable Energy and Energy Efficiency' according to UNDP.

\section{c) Yemen Future Renewable Energy Mix}

As it affects the concepts of mix with regards to the renewable energy mix, the prospects and potential for Yemen to centralize, expand and diversify its alternative energy options such as 'Solar Energy' potentially will be discussed in the next section below.

\begin{tabular}{|c|c|c|c|c|}
\hline Wind & $\begin{array}{c}\text { Concentrated } \\
\text { Solar Power }\end{array}$ & Biomass & Geothermal & Hydro \\
\hline $56 \%$ & $14 \%$ & $0.08 \%$ & $28 \%$ & $0 \%$ \\
\hline
\end{tabular}

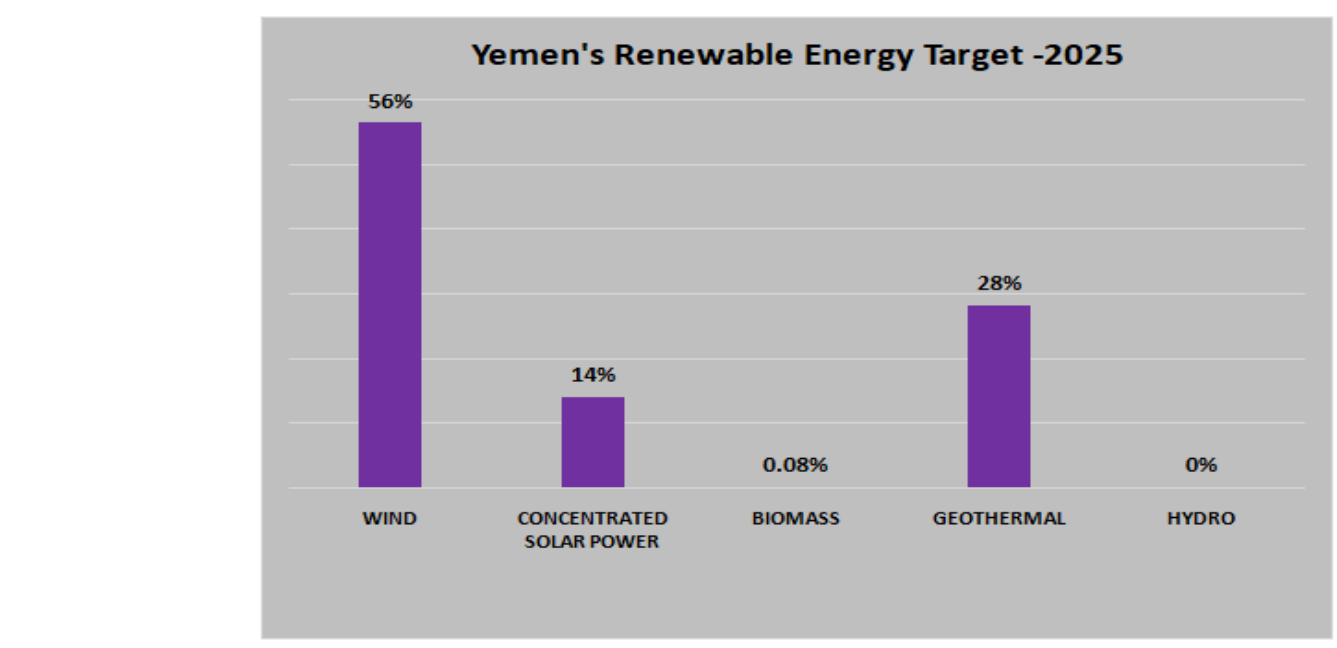

Source: Republic of Yemen's National Strategy Centre for Renewable Energy and Energy Efficiency

Figure 4: Future targets of Yemen's Share of Renewable Energy Mix

The graphical concept as demonstrated in the future target of the potential of renewable energy of Yemen, with an increase of $15 \%$ in total renewable energy contribution to the country's power sector has highlighted that the least appropriate option for this country is hydro or water power set at $0.08 \%$ because in Yemen, the whole country is arid and very dry.

Yemen is usually described as xeric and it implies that the country is mostly 'desert' based on the notion that it has a high hinterland, semi-desert and extensive coastal plains through the Arabian Sea and the Red Sea (Carapico, 1998). Yemen is characterized by clear and hot weather. Generally speaking, the temperature in Yemen is usually very high, especially in desert and coastal areas. It has been noted by the geographically Lichtenthaler (2003), Yemen located in the area described as Sunbelt in the world. The country is naturally authorized by radiation from the sun that ranges from 6.8 to $5.5 \mathrm{kWh} / \mathrm{m}^{2}$ daily and daily average sun rays range from 7.3 and 9.1 hours daily. The average approx. 8 hours of sunshine each day is also witnessed in Yemen even during the winter period (Ali et al., 2014).
In such a case, it is clear that Yemen is naturally endowed because it has the capability and potential to make full use and generate electricity through solar power to power and to power many Yemeni households in the interior to bridge the gap in electricity supply in the area - Desert and poor areas. At present, Yemen's natural potential to capitalize on Yemen's potentially more solar energy than the minimum radiation of solar as well as the long hours of sunlight received by the country even during the winter is clear that Yemen can easily use and innovate solar technologies to utilize power from the sun in a sustainable way. Consequently, it is wise to highlight that external solar power and grid on the grid have the ability to contribute Supplying solar power in form of electricity can easily be achieved in Yemen via a technological process in which the radiation from the solar power panels is converted into electric power either directly by utilizing (PV) photovoltaic systems or the country can choose to indirectly convert solar light into electricity by utilizing (CSP) -concentrated solar power modules (Moe and Midford, 2014). 
There are many benefits that can be obtained from solar power generation if the Yemen government can formulate a support policy that will bring solar energy awareness into a renewable energy form across the country. The overall benefits of solar energy depend on social, economic and environmental aspects. First of all, the main advantage of solar energy production in Yemen highlighted that solar energy is highly sustainable because its technology relies entirely on heat radiation from sun-powered light from using fossil fuels, non-renewable forms of energy that will definitely decline (Waltz, 2015; Jackson, 2009).

Second, solar energy does not pollute the environment unlike fossil fuel that pollutes and lowers the environment. There are zero Greenhouse Gas emissions from solar and social and environmental energies. For example, solar energy panel maintenance and service costs are minimal and it has a lifespan of about 20 years or more, thereby ensuring a better form of energy (Moe and Midford, 2014).

Instead of using diesel generators during the distribution of 'Public Electricity Corporation' alternately in Yemen, solar energy can provide a better alternative in terms of bridging the gap in terms of electricity supply to rural and urban areas. By training many Yemenis on the concept of solar energy and generating electricity, employment can also be created for unemployed by equipping them with relevant skills that can be used to work in the energy sector.

\section{Conclusion}

Yemen has unexplored potential to use solar energy as a way to fill the country's energy gap. Unfortunately, the country's solar energy market is still lagging behind in producing maximum capacity that will help the country to improve its short-term energy supply in rural areas based on a number of preventive factors including a lack of policy and facilitator framework from the government to fully support solar energy initiatives to help the country reducing its dependence on fossil fuels. Furthermore, high pricing costs for setting solar power devices are also a reduction factor but the cost of maintaining solar power generation facilities is very minimal in the long run. However, UNDP has insisted that Yemen has the potential to fully settle its dependence on fossil fuels if the country can adopt solar energy and other forms of renewable energy to restrict the development of new fossil fuel generation power in the country. It is also permissible to highlight that UNDP also states that 'developing an appropriate national solar capacity involving dedicated financial mechanisms and cost-effective cost instruments will continue to contribute towards enhancing solar power prospects in Yemen while at the same time having a tendency to create jobs new and supporting the development of solar energy in the country.

\section{References Références Referencias}

1. Al Ashwal , A. M. (2005). All Renewable Energy Applications in Yemen are Best Practice. ISESCO Science and Technology Vision, 1, 45-50.

2. Al Ashwal, A. M. (2016). Energy efficiency and conservation indicators in Yemen. Future Cities and Environment, 2(3). doi:10.1186/s40984-016-0016-0.

3. Al Kholidi , A. G. (2013). Renewable Energy Solution for Electrical Power Sector in Yemen. International Journal of Renewable Energy Research, 3(4).

4. Al Kubati, M., Mattash, M. A., Alnethary, M. F., Minissale, A., \& Vasseli, O. (19-25 April 2015). Geothermal Exploration and Geothermometric Characteristics of Western Area in Yemen. Paper presented at the World Geothermal Congress 2015, Melbourne, Australia.

5. Ali, W., Alkadasi, F., \& Khoday, K. (2014). Prospects of Solar Energy in Yemen. Retrieved from.

6. Creutzig, F., Agoston, P., Goldschmidt, J. C., Luderer, G., Nemet, G., \& Pietzcker, R. C. (2017). The underestimated potential of solar energy to mitigate climate change. Nature Energy, 2(9), 17140.

7. Jahangiri, M., Ghaderi, R., Haghani, A., \& Nematollahi, O. (2016). Finding the best locations for establishment of solar-wind power stations in Middle-East using GIS: A review. Renewable and Sustainable Energy Reviews, 66, 38-52.

8. Qasem , A. Q. S. (2018). Applications of Renewable Energy in Yemen. Journal of Fundamentals of Renewable Energy and Applications, 8(1). doi:10.4172/2090-4541.1000254.

9. Rawea, A., \& Urooj, S. (2017). International Journal of Renewable Energy Research, 7(1).

10. Sufian, T., Ogutcu, C., \& Barra, M. (2017). Energy Investment and Business Climate Report for Observer Countries. Retrieved from Energy Charter Secretariat, Boulevard de la Woluwe, 46B-1200, Brussels, Belgium: https://energycharter.org/fi leadmin/DocumentsMedia/Occasional/Yemen_Inves tment_Report.pdf.

11. Timmons, D., Harris, J. M., \& Roach, B. (2014). The economics of renewable energy. Global Development And Environment Institute, Tufts University, 52.

12. World Bank Group (2013) Economic Growth in the Republic of Yemen: Sources, Constraints and Potentials -Word Bank Country Studies. Washington D. C USA: World Bank Group Publications. 